\title{
Erythema multiforme syndrome associated with acute acquired cytomegalovirus infection
}

\author{
Marianna Immacolata Petrosino, Marina Attanasi, M. Loredana Marcovecchio, \\ Alessandra Scaparrotta, Sabrina Di Pillo, Nadia Rossi, Francesco Chiarelli
}

Department of Pediatrics, University of Chieti, Chieti, Italy

Submitted: 18 June 2014

Accepted: 9 September 2014

Arch Med Sci 2016; 12, 3: 684-686

DOI: 10.5114 /aoms.2016.59943

Copyright @ 2016 Termedia \& Banach

A 7-year-old boy was admitted to the pediatric ward (University of Chieti) for the onset of multiple erythematous target lesions, some with vesicles in the middle, located on the ears, face (Figure $1 \mathrm{~A}$ ), in the oral cavity (Figure 1 B), on both hands, feet and lower limbs. Four days prior to admission the patient presented prodromal symptoms, such as fever (maximum temperature $38^{\circ} \mathrm{C}$ ), sore throat and asthenia. All these features supported a diagnosis of erythema multiforme (EM) secondary to an infection. Blood examination revealed lymphopenia $(1.28 \times 10,000 / \mu \mathrm{l})$, neutrophilia $(6.10 \times 10,000 / \mu l)$, erythrocyte sedimentation rate of $15 \mathrm{~mm} / \mathrm{h}$ (normal range: $1-12 \mathrm{~mm} / \mathrm{h}$ ) and alanine aminotransferase of $80 \mathrm{U} / \mathrm{l}$ (normal range: 11-66). Serum antibodies against Mycoplasma pneumoniae, Adenovirus, Varicella Zoster, Epstein-Barr virus and Herpes Simplex Virus (HSV) 1 and 2 were negative. In contrast, cytomegalovirus (CMV) IgM antibody titers were positive $(23.6 \mathrm{U} / \mathrm{ml}$; normal range: 0 to 18), whereas IgG antibody values were normal ( $<5 \mathrm{U} / \mathrm{ml}$; normal range: 0 to 12). Four weeks later, the levels of anti-CMV IgG antibodies rose $(190 \mathrm{U} / \mathrm{ml})$ with normalization of anti-CMV IgM levels. During hospitalization, management included intravenous fluids and electrolyte infusion for skin and mucosae dehydration and for the poor oral intake due to an intense oral burning sensation; methylprednisolone $(0.8 \mathrm{mg} / \mathrm{kg} / \mathrm{day})$; intravenous antibiotic therapy (ceftriaxone) to prevent skin bacterial infection, because the patient (unable to take oral drugs for the several lesions in the oral cavity) presented fever and neutrophilia $(6.10 \times 10,000 / \mu \mathrm{l})$ and mild elevation of erythrocyte sedimentation rate $(15 \mathrm{~mm} / \mathrm{h})$.

The erythematous vesicular lesions gradually improved. Erythema multiforme is a rare, acute, self-limiting, immune-mediated hypersensitivity reaction [1] in children and it is exceptional in newborns [2]. Erythema multiforme presents over a period of 12 to $24 \mathrm{~h}$. A relatively mild prodromal phase that resembles an upper respiratory infection usually occurs before the skin eruption. The papular lesions appear symmetrically on the extremities and are target-shaped, with 3 different-colored zones and a blister in the center clearly demarcated from the surrounding skin. Mucosal disease is typically restricted to the oral mucosa [3]. The precise incidence of EM is unknown, but it has been postulated to be less than $1 \%$ but probably greater than $0.01 \%$ [4]. Several factors have been suggested to be associated with the development of EM, such as infections (90\%, particularly HSV and Mycoplasma pneumoniae), medication use, autoimmune disease, malignancy, immunization, radiation, and menstruation [4]. Erythema multiforme can also be

\author{
Corresponding author: \\ Alessandra Scaparrotta MD \\ Department of Pediatrics \\ University of Chieti \\ Via dei Vestini 5 \\ 66100 Chieti, Italy \\ Phone: +390871358690 \\ E-mail: ale.scaparrotta@ \\ libero.it
}



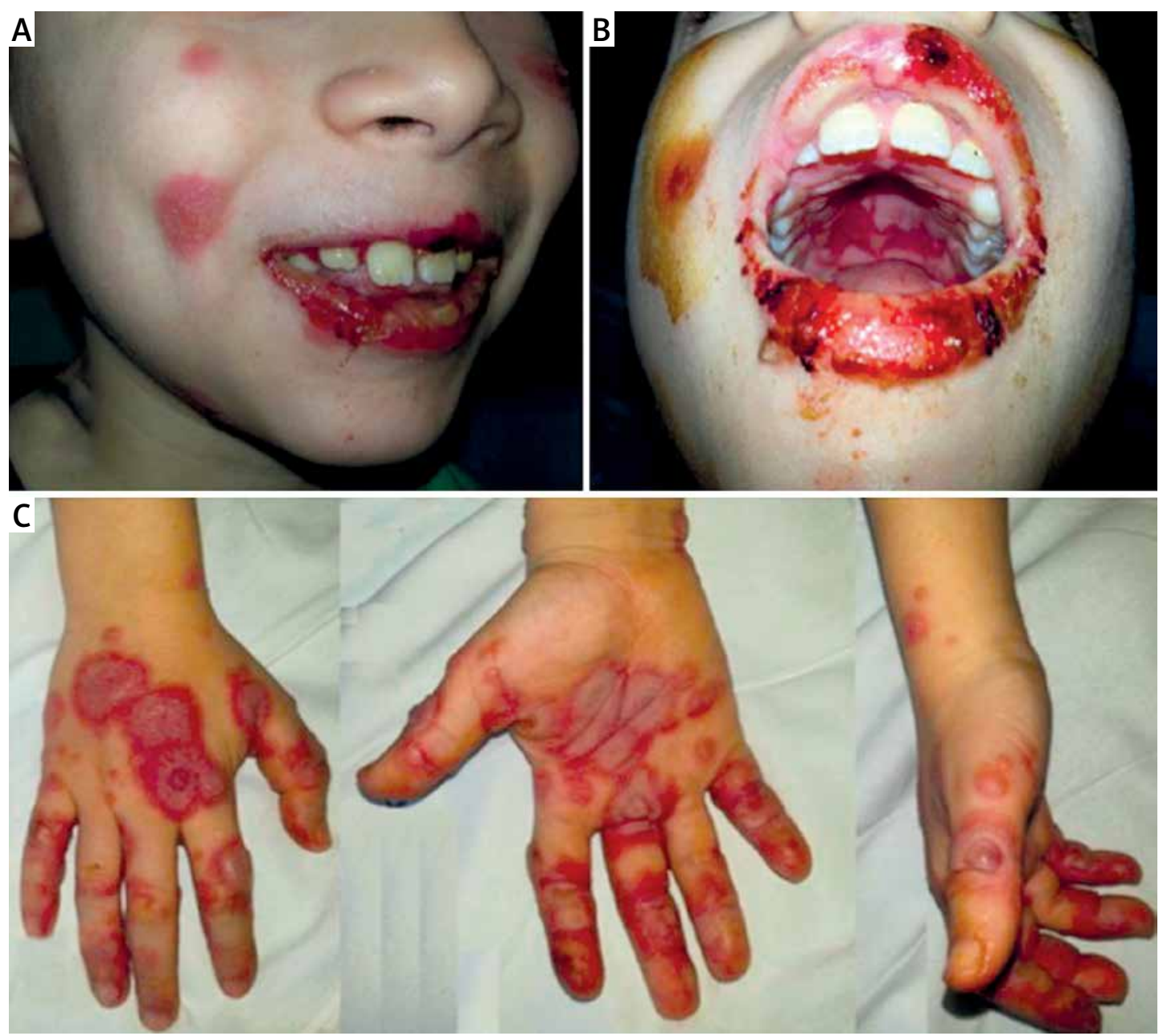

Figure 1. The erythematous and vesiculo-bullous lesions on the face (A), numerous injuries in the oral cavity (B) and lesions on the hands (C)

an early cutaneous manifestation of a particular disease, such as Lyme disease [5], a multi-organ animal-borne disease, caused by spirochetes of Borrelia burgdorferi, which typically affect the skin, nervous system, musculoskeletal system and heart [6]. In our patient, a role of CMV infection seemed highly plausible, due to the temporal relationship between the skin and mucosa lesions and the changes in the antibodies against CMV. Furthermore, our patient did not have any history of other past infectious diseases or drug use, therefore ruling out the possibility of EM related to drugs or other infections. To our knowledge only some cases of EM associated with CMV infection are reported in children and in adults [7] and one case in a newborn [2]. In HSV-associated EM, the findings are thought to result from a cell-mediated immune reaction against viral antigen-positive cells that contain the HSV DNA polymerase gene. A number of subjects with EM is genetically predisposed to develop EM. A study [8] revealed the role of the HLADQB1*0301 allele, which is important particularly for patients with HSV-associated EM. However, the diagnosis of EM is a clinical one [9].
The severity of EM and mucosal disease varies between patients. For this reason, management should be personalized for each patient. Mild cutaneous EM can be treated primarily with a goal of achieving symptomatic improvement. Hospitalization is necessary in the presence of severe mucosal disease that produces poor oral intake and subsequent fluid and electrolyte imbalance [4]. Some clinical evidence suggest treating minor EM with topical steroids. The use of systemic steroids for EM major remains controversial, as there is evidence both for and against treatment, and no randomized controlled trials have been performed [10]. Other studies are necessary to determine the effectiveness of these therapeutic approaches. This case report provides a rare clinicopathological correlation in pediatric age, because although already but rarely reported in the literature, it highlights the need to consider CMV infection as a potential cause of EM in patients without a history of other infections (particularly HSV and Mycoplasma pneumoniae), drug intake or other causes (autoimmune disease, malignancy, immunization, radiation). It can be useful in the 
future to estimate the incidence of the various pathogenic agents that can cause EM, and it also provides significant images of this serious disease that can help clinicians in diagnosis. On the other hand, it provides another experience in the use of corticosteroids in these patients, supporting the usefulness of these drugs in children with EM.

\section{Conflict of interest}

The authors declare no conflict of interest.

\section{References}

1. Ladizinski B, Carter JB, Lee KC, Aaron DM. Diagnosis of herpes simplex virus-induced erythema multiforme confounded by previous infection with Mycoplasma pneumonia. J Drugs Dermatol 2013; 12: 707-9.

2. Cieza-Díaz DE, Campos-Domínguez M, Santos-Sebastián Mdel $\mathrm{M}$, et al. Erythema multiforme in a newborn associated with acute acquired cytomegalovirus infection. Pediatr Dermatol 2013; 30: e161-3.

3. Segal AR, Doherty KM, Leggott J, Zlotoff B. Cutaneous reactions to drugs in children. Pediatrics 2007; 120: e1082-96.

4. Sokumbi O, Wetter DA. Clinical features, diagnosis, and treatment of erythema multiforme: a review for the practicing dermatologist. Int J Dermatol 2012; 51: 889-902.

5. Schuttelaar ML, Laeijendecker R, Heinhuis RJ, Van Joost T. Erythema multiforme and persistent erythema as early cutaneous manifestations of Lyme disease. J Am Acad Dermatol 1997; 37: 873-5.

6. Biesiada G, Czepiel J, Leśniak MR, Garlicki A, Mach T. Lyme disease: review. Arch Med Sci 2012; 8: 978-82.

7. Seishima M, Oyama Z, Yamamura M. Erythema multiforme associated with cytomegalovirus infection in nonimmunosuppressed patients. Dermatology 2001; 203: 299-302.

8. Khalil I, Lepage V, Douay C, et al. HLA DQB1*0301 allele is involved in the susceptibility to erythema multiforme. J Invest Dermatol 1991; 97: 697-700.

9. Krippaehne JA, Montgomery MT. Erythema multiforme: a literature review and case report. Spec Care Dentist 1992; 12: 125-30.

10. Chan M, Goldman RD. Erythema multiforme in children: the steroid debate. Can Fam Physician 2013; 59: 635-6. 